\title{
Thais put their faith in folk medicine
}

In first of two articles on scientific issues in Thailand, David Bousfield of the University of Sussex describes how religion and medicine often go hand in hand

TRADITIONAL health care systems based on herbal preparations still exist in many developing countries today, and although often despised in the recent past they could provide a focus for the development of local pharmaceutical industries and research. Plants are already important sources of established drugs such as diosgenin (a precursor of many steroids), codeine and atropine. They may also contain compounds with novel actions. The massive screening of plant extracts for anti-cancer drugs carried out under the auspices of the National Cancer Institute, and the research currently being coordinated by the World Health Organisation on physiological bases of folklore contraceptives are good examples of the current interest in this field. In addition, by employing an indigenous health care structure, medical treatment may begin to penetrate rural areas where previously there was no help at all.

South-east Asia provides some useful examples of the possibilities and limitations of integrating this traditional knowledge with the medical needs of a developing society.

In Bangkok alone there are more than fifteen traditional medical schools, some of which can be found on the grounds of Buddhist temples. Wat Poh, the temple of the Reclining Buddha, for example, has long been an important centre for folk medicine in Thailand. In the provinces, such as Chiang Mai in the north, herbal pharmacies are common and are often found beside, or even inside, their modern counterparts.

Certain Buddhist monks, the 'maw phra' or 'doctor bhikku', play an important role in treating rural sick. In some cases these schemes can be very ambitious. The Abbot, Phra Chamroon Parn Chan, of the temple Wat Tham Krabok has recently been given the Ramon Magsaysay Award (a south-east Asian equivalent of a Nobel Prize, named after the late Filipino President) for his work with drug addicts. His approach relies heavily on herbal infusions "to clear poisonous drug residues from the body", thus eliminating "the physical desire for narcotics". With government subsidies the Phra hopes to be able to treat up to 4,000 addicts annually.

Doctor Bhikkus self-trained bare-foot 'tambol' doctors are very popular among the lower educated, lower income groups in both rural and urban districts. Several government training schemes are in

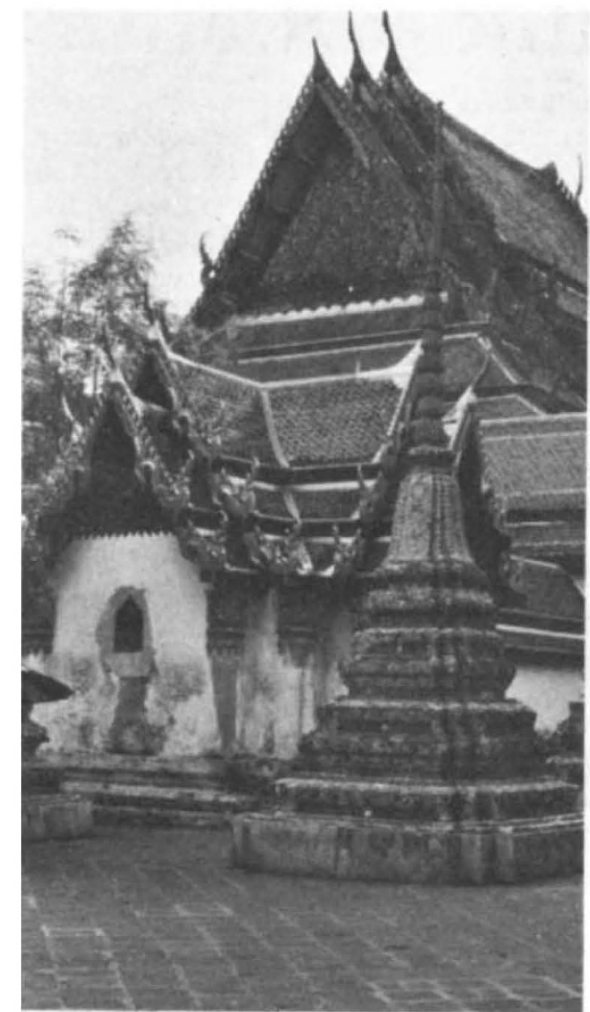

Wat Poh temple, Bangkok, which houses a number of traditional medical schools

existence which aim to improve this service in areas such as nutrition and family planning. Use of herbal medicines is taught in many university departments of pharmacy and pharmacology, and in some cases students may even attend additional courses at their local traditional school of medicine.

Research is well under way on the extraction, identification and characterisation of the physiological, pharmacological and toxicological properties of the active principles present in a number of crude drugs. Particular areas of interest include the studies of alkaloids present in local Rauwolfia species, some of which could provide a commercial source of drugs such as reserpine. 'Kinchai', Chinese celery (Anium graveolens), is also being studied for its potent hypotensive actions and its dramatic ability to reduce temporarily sperm count in man. In Chiang Mai research is being carried out on extracts from a variety of plants including a Curcuma (Zingiberaceae), locally known as 'Wan $\mathrm{Ngu}$ '. This contains an inhibitor of cobra and viper neurotoxin, and the study of the properties of this extract and its active ingredients has stimulated an exciting amount of neurophysiological and neuropharmacological research. The universities of Mahidol and Chulalongkoru in Bangkok are carrying out even more intensive studies.

The development of useful drugs based on natural product 'diospyrol' serves as a good example. Roundworms, hookworms and other parasitic infections are a serious health problem throughout south-east Asia. In Bangkok's slums 2\% of the children have Ascaris infections and 6\% hookworm. In rural areas the prevalence of hookworm can exceed $80 \%$, with anaemic complications in half the cases. Effective drugs for treatment do, of course, exist but are often unavailable in the more remote parts of the country. On the other hand, the tree 'Ma-gluea' (Diospyros mollis, Griff) which is indigenous to northern and central Thailand has long been recognised for the anthelminthic activity of its berries. The fresh fruit is crushed with a small amount of water, strained, and mixed with coconut water to mask its disagreeable taste.

Clinical trials have shown that the drug is effective against a wide variety of intestinal parasites, and the limited field testing which has been carried out has met with encouraging results. The plant, however, only bears fruit in the rainy season (June to October) and the remedy is only effective if the berries are fresh. A good deal of work, conducted mainly by the Ministry of Public Health in collaboration with Japan, has therefore gone into identifying the active principle, 'diospyrol', a methylated binaphthyl compound, and to discovering methods of preserving the extract. This work was completed in the late $1960 \mathrm{~s}$, but since then little has been done to develop herbal medicines to a commercial level.

Research into natural products and herbal medicines is being carried out on a similar scale in at least nine neighbouring countries. These are Thailand's four partners in ASEAN - Indonesia, Malaysia, Singapore and the Philippines plus Japan, Korea, Hong Kong, Australia and New Zealand. Together, they make up the Network for the Chemistry of Natural Products in South East Asia, a Bangkokbased organisation funded mainly by UNESCO and the Japanese government. It is, however, clear that serious problems occur whenever the commercial exploitation of a natural product medicine becomes a possibility.

Ironically this may be the result of the United Nations Industrial Development Organisation (UNIDO) plan for the establishment of drug industries in Third World countries, which involves a backward integration approach to drug manufacture. UNIDO feels that each country should begin with setting up packaging plants, then move on to formulation of imported bulk drugs, and finally manufactures the bulk drugs themselves. But in countries such as Thailand such an approach could stifle the motivation behind much of the current research into herbal medicines and result in many of these new compounds being developed and sold by the multinational pharmaceutical companies. 